\title{
World Energy Saving from Cars: An Innovative and Feasible Proposal
}

\author{
Luis Eduardo Juanicó \\ Department of Advanced Designs, Bariloche Atomic Center, P.O. Box 8400, Bariloche, Rio Negro, Argentina \\ Correspondence should be addressed to Luis Eduardo Juanicó, juanico@cab.cnea.gov.ar
}

Received 30 June 2011; Accepted 15 August 2011

Academic Editors: W. He, F. E. Little, and V. Makareviciene

Copyright () 2011 Luis Eduardo Juanicó. This is an open access article distributed under the Creative Commons Attribution License, which permits unrestricted use, distribution, and reproduction in any medium, provided the original work is properly cited.

\begin{abstract}
Many devices have been proposed for energy saving (by heating water) from the waste heat of car engines, some dating as far back as the early 1900's. However, so what this heated water could be used for remains an open question. In this paper, a new proposal is presented to answer this question. This is an onboard car and on-ground systems, for heating water to be used for the benefit of the community, as this hot water would be applied to meet the heating demand in buildings. Concerns about the added mass on the car, costs, and benefits and the user interface were discussed, and a universal system that could satisfy all of these criteria was developed.
\end{abstract}

\section{Introduction}

In 1900 only 4,192 passenger cars were built in the United States (the only country to be manufacturing cars at that time) [1]. By 1985 there were one hundred million cars in existence. Today, with dozens of countries participating in the manufacture of automobiles, that number is six times higher. It is believed that at this rate, the number of cars on earth will double within the next 20 years, China and India booming.

The autoboom will only add to the world's thirst for petroleum and spew even more carbon dioxide into the air. Among key assumptions underlying these projections, experts believe that alternative fuels and radical technological innovations will not significantly penetrate the market [2]. Rising demand for motor-vehicle fuel is "perhaps the most strategic development in international oil-and-gas geopolitics," says Fatih Birol, chief economist of the International Energy Agency [2]. That will force the autoindustry to deal with rising demands for fuel efficiency and pollution control, for both environmental and political reasons.

The efficiency of various types of internal combustion engines varies. It is generally accepted that engines with the best gasolina-fueled internal combustion have a mechanical efficiency of about 20\%. Most internal combustion engines waste about $36 \%$ of the energy in gasoline as heat lost in the cooling system and another 38\% through the exhaust. The rest, about $6 \%$, is lost to friction [3]. Hence, meanwhile, there is only little margin for future improvement on motor efficiency, more than two thirds of the fuel energy is released as heat to the environment.

Most engine manufacturers have done little to harness this wasted energy though there are various add-on devices and systems that are known to significantly recover wasted energy. On the other hand, this issue has been widely studied for on-ground large-engine generators. For these, it is economical and technical feasible to install cogeneration systems [4]. However, the application of these techniques onboard cars is rather different. In this case, it is imperative to consider costs, simplicity of operation, and weight. As the engine is used intermittently, high-investment solutions are not affordable; technician supervision will not be available, and vehicle mobility must not be penalized by excessive overweight.

Many inventors have been developing devices for heating water by using the motor exhaust or its cooling system for a century $[5,6]$. Summarizing, these inventions consist of a water tank, that is (1) placed surrounding the exhaust 
pipe or (2) introducing the piping of the cooling system inside it. In both cases, the proposed system would do this without mixing the streams by using a kind of shell-tube heat exchanger. In both cases, the purpose is exchanging and storing the heat wasted by the car engine in this supplementary water inventory, which can be designed so that it does not interfere with the engine operation. In the second case (the cooling system), the only precaution to be taken is to use the cooling tube section between the thermostat valve and the radiator (this way, the supplementary tank actually works as another radiator) and not to use the tube section between the engine and the thermostat valve. For the first case, the proposed system is related to the exhaust piping only externally in an essentially nonperturbative manner. Indeed, since the exhaust gases are cooled, (and hence, their velocity reduced) the pressure drop along the exhaust piping is reduced accordingly, and so motor efficiency could be even slightly improved.

The amount of energy released by cars into the environment is huge. Burning just one gasoline gallon in the most efficient engine and assuming a regular efficiency of $70 \%$ for the heat interchanger, about 90 liters of water could be warmed up from $10^{\circ} \mathrm{C}$ to $100^{\circ} \mathrm{C}$, by using just one of the two systems described above. But, what would be the use of such heated water in a car? This seems to be an open question, considering the fact that no car has yet been built applying these ideas.

\section{The New Proposal}

The present proposal consists of a new approach focusing on this last question. We consider this subject not from an "onboard" point of view, but instead and by using an "outof-box mind," from the community's point of view. In this sense, such inventory of hot water could be useful to satisfy the large energy requirements for household space heating. Let us remark that energy consumption in buildings accounts for $40 \%$ of the present total energy consumption in OECD countries.

An average one-family house in cold climate areas (like Sweden) has annual energy consumption for space heating of around $50 \mathrm{GJ}\left(0.5 \mathrm{GJ} / \mathrm{m}^{2} / \mathrm{y}\right)$. Thus, by recovering as hot water $70 \%$ of the energy wasted in cars (by using simultaneously both systems proposed), this demand could be met by burning 70 gasoline gallons per month, which could be considered average for two car families. Thus, by taking the projected global use of petroleum-based fuel in cars and light trucks by the year 2030, it could save the total heating demand of about 600 million Swedish homes or roughly estimated, up to double homes in European average climates.

This proposal involves two parts. First, by equipping any car with a water heating system such as the ones described above. Second, building many recharge points in the community where drivers can dispense the heated water from short trips to school, the hospital, and so forth.

Relating to the first part, these systems can be installed in every car, light truck, buses, and other vehicles with combustion engines. A 90 liter tank is suggested for a medium car $(1,300 \mathrm{~kg}$ weight), and proportionally greater for bigger vehicles. Let us note that since the added weight is less than $10 \%$ of the car, it will not cause a noticeable overload on the shock absorber system, nor on travel efficiency. The energy consumed for transport is due to two major causes: friction with the road and air drag forces, this last remaining unchanged. The added weight has a contribution in the losses due to friction with road and kinetic energy. Kinetic losses represents less that $1 \%$ of the total for an average trip. In low-speed urban transport kinetic energy is low; meanwhile in high-speed highway transport, the frequency of breaking is low. Moreover, it could be even less for a modern hybrid car that can recover kinetic losses. Regarding this point, another advantage of the proposed onboard system is that it can be omitted at any time as needed, (e.g., driving with excess weight) by simply discharging its water inventory. Road frictional losses represent about half of the total transport losses in an average urban trip, and less on highways (in which air drag losses are predominant). Regarding Coulomb's law, frictional force is proportional to car mass. Hence, total losses added are around 5\% that represents only a slightly increasing in the fuel consumption. This consumption is little compared to the energy saved as heat. According to our previous estimation, energy saved could represent up to $50 \%$ of the total fuel energy (by using both systems proposed and if all heated water is efficiently utilized for a secondary purpose, like building space heating), doubling present car efficiencies.

\section{Practical Engineering Solution}

We are proposing now an engineering solution specially developed for application in the community. One remarkable innovation is the simplicity of operation and the low-cost and universal applicability of the onboard device. Problems regarding (a) interface between users and building heating systems, (b) user delays due to the charge and discharge process, and (c) management of the tank overpressure due to water thermal expansion are all solved by means of the on-ground system designed here. This system would be installed at each interchange station in the community (shopping, hospitals, schools, etc.). Since the onground system is intended for many cars, this configuration allows us to keep the investment for the complete system low, simultaneously preserving the onboard characteristics claimed (simplicity, easy operation, low costs, universal manufacture, and easy installation). These are key features aimed at providing large-scale applications.

The device designed for the cooling motor's system is a flat square tank (about $1 \mathrm{~m} \times 1.5 \mathrm{~m}, 6 \mathrm{~cm}$ height; see Figure 1) with a water capacity of 90 liters and with a metallic coil ( $3 \mathrm{~m}$-length $2^{\prime \prime}$-diameter) built in. This system works as a shell-tube heat exchanger, heating the tank water with the hot water flow used for motor cooling. This tank is connected to the charge and discharge system by a couple of flexible hoses that can be fixed to the car mudguards. This design was chosen because it could be installed behind the motor of almost any car. For larger vehicles, in which a large water inventory can be used, so, it is possible to arrange many interconnected tanks like this one. In this way, the device can 


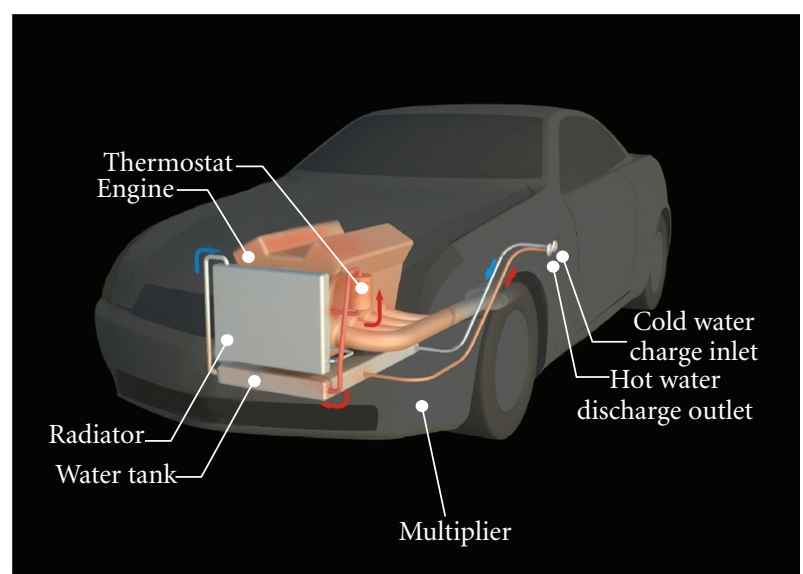

FIGURE 1: Schematic draw of the proposed on-board device for the cooling motor's system.

be universally manufactured by any tank manufacturer, and installed and operated by average users.

The device designed for the exhaust motor's system is a slender tank $(0.1 \mathrm{~m} \times 0.5 \mathrm{~m}$ section, $2 \mathrm{~m}$ length; see Figure 2$)$ designed for substituting the present exhaust system. The exhaust pipe is built in the bottom of this tank, in order to improve heat transfer to the water. Considering the high temperature of the heat source, it is necessary to control the flow of hot gases inside the water tank. This problem could be solved by designing a secondary external exhaust pipe with a two-way valve and control system that changes the path of the exhaust gases when the water reaches $95^{\circ} \mathrm{C}$.

Both devices can heat the water inventory up to $80^{\circ} \mathrm{C}$ in half an hour for average car use, as we shall see in the next section. Although the water is not allowed to boil, its thermal expansion can cause significant overpressure on the tank if no pressure control is provided. According to the water's expansibility, a $5 \%$ volume increase is observed for heating water from $10^{\circ} \mathrm{C}$ to $80^{\circ} \mathrm{C}$. Since the simplest tank is one formed with a single rigid chamber constructed with metallic walls, this volume increase would cause a nonmanageable over pressure, and as a consequence damage to the tank. For this reason, most conventional water heating systems, like boilers, have to provide for this thermal expansion by using a secondary vacuum volume to release the increasing pressure. However, this common solution (and the complexity involved) is not feasible for the low-cost and low-weight on-board device.

Therefore, a new approach is proposed for the previous problem. It is based on the integrated approach of combining the on-ground and onboard systems instead of providing an isolated solution for the onboard system. In this way, the onboard system remains quite simple, transferring all the control features to the on-ground system. This system can be used to serve many cars in the community and does not have limitations of weight and space.

The water charge and discharge process would be controlled by the on-ground system. First, the heated water can be discharged very quickly into a small system's tank using a water pump that aspires from one inlet while compressed air is injected into the other inlet. The water temperature and volume delivery can then be monitored in order to compensate the user if this is considered. Occasionally, if the users do not want to recharge water, the process can end here without wasting water. When the water discharge is completed, the tank is quickly refilled by pumping cold water after producing a vacuum. When the tank is full, the system equalizes the tank and atmospheric pressures. Finally, a calculated (about $10 \%$ of the tank volume) air volume is injected, in order to obtain a two-phase mix. This air bubble is used during the heating cycle for absorbing the thermal water expansion. In this way, the overpressure caused by thermal expansion is up to 2 bar, being a manageable value.

When the interchange process is completed, the onground systems delivers the hot water collected into a large reservoir tank inside the building and into its heating system (see Figure 3). Hence, this hot water can be used directly by end users, for example, baths and laundries. Besides, it can be used by the building space heating system (that uses a closed water cycle) providing a low-cost heat exchanger inside this tank that preheats the water before the boiler inlet. In this way, the standard heating system is not really modified, and the hot water demand and supply can be easily matched. The boiler's burner is shut down when this preheating is enough to fully satisfy the heating demand of the building; otherwise, the burner power is used to control the water temperature exiting the boiler, as in every boiler.

\section{Thermal Analysis}

Let us consider the thermal performance of both devices proposed considering a one-dimensional model, which is suitable for the conceptual level of this study. Therefore, the performance of the heat exchange can be studied using the one-dimensional thermal resistance approach, on which the total resistance $R$ is the sum of both, the convective resistant of internal flow $\left(h_{i}\right)$ and external flow $\left(h_{e}\right)$, by

$$
\frac{1}{U}=R=\frac{1}{h_{i}}+\frac{1}{h_{e}}
$$

where $U$ is the global conduction coefficient, which is mostly used to calculate the power of heat transferred $(Q)$ through the wetted wall area $(A)$ by the temperature jump $(\Delta T)$ between the hot $\left(T_{h}\right)$ and cold $\left(T_{c}\right)$ temperatures, being

$$
Q=A U\left(T_{h}-T_{c}\right)
$$

The convection coefficients can be calculated from engineering correlations, usually expressed by the dimensionless Nusselt number $\left(\mathrm{Nu}_{D}=h D / k_{f}\right.$, being $k_{f}$ the fluid conductivity and $D$ the tube diameter). The Dittus-Boelter correlation is generally used for internal turbulent flows [7]

$$
\mathrm{Nu}_{D}=0.023 \operatorname{Re}^{0.8} \operatorname{Pr}^{0.3}
$$




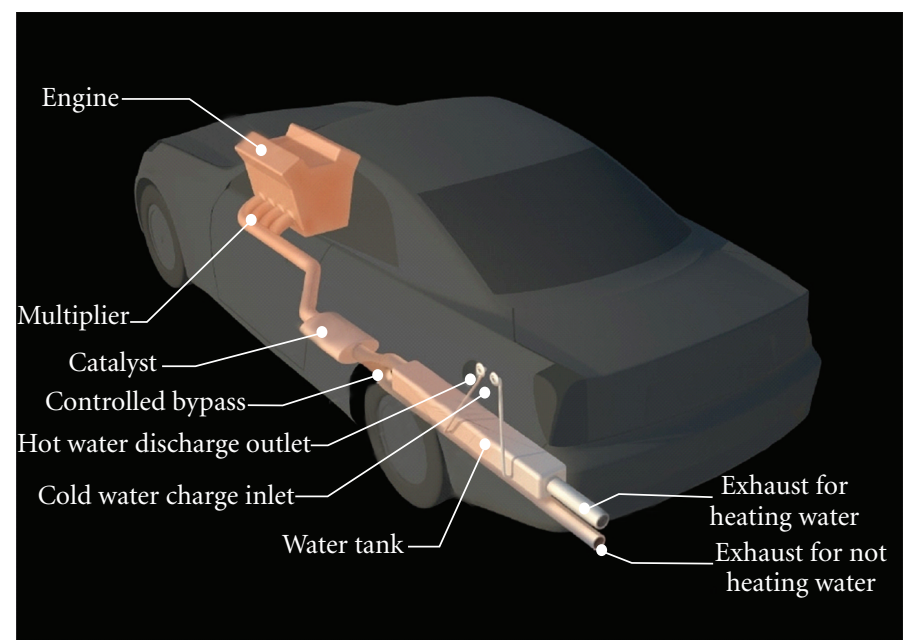

FIGURE 2: Schematic draw of the proposed on-board device for the exhaust gases system.

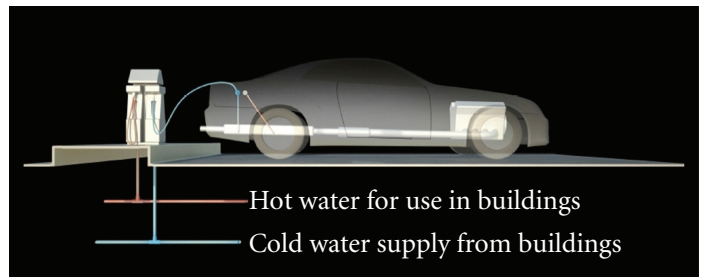

FIgURE 3: Schematic draw of the proposed on-ground system.

where Re and Pr are the Reynolds and Prandt numbers of the flow. On the other hand, for free convection flow surrounding a horizontal cylinder, a suitable correlation is [7]

$$
\mathrm{Nu}_{D}=0.0125 \mathrm{Ra}^{0.333}
$$

where $\mathrm{Ra}$ is the Rayleigh flow number. The heat transfer, $Q$, can be related to the water temperature increasing rate $(d T / d t)$ by the energy balance

$$
Q=M c \frac{d T}{d t}
$$

Equations $((1)-(5))$ can be used to determine the time evolution of the water tank temperature, $T_{c}(t)$. Let us consider a car motor of $100 \mathrm{~kW}$ working on a steadystate half-load regimen $(50 \mathrm{~kW})$. Hence, the motor's cooling system delivers $18 \mathrm{~kW}$ by pumping $m^{\prime}$ water mass flow at $90^{\circ} \mathrm{C}$. We can estimate $m^{\prime}$ considering that it must be designed for the full-power condition $(Q=36 \mathrm{~kW})$ and considering $\Delta T=40^{\circ} \mathrm{C}$ as the cooling jump through the radiator, from its energy balance. The calculated parameters are summarized in Table 1 for both cases.

An additional improvement is obtained for the exhaust gases system, besides the possibility of heating the water to higher temperatures. In this case, when the hot gases are cooled from $1,000^{\circ} \mathrm{C}$ to $200^{\circ} \mathrm{C}$, its velocity is reduced to one third. This feature can be very useful for designing new exhaust system with a much lower pressure drop, and accordingly motor efficiency could be improved too.

Regarding the very high temperature of exhaust gases, it allows us to explore new applications for the heated water. We are presenting here only preliminary another new proposal. The water could be boiled off and condensed obtaining distilled water, a highly valuable food in many developing countries. Conversely, the water inventory of the tank could be noticeable reduced, according to the very high heat of phase change involved up to seven times. This system could be especially suitable for large vehicles where space limitations may be minor issues, like heavy trucks and even better, railway locomotives. Locomotives are the best choice because their almost negligible friction losses. So, concerns about mass (and volume) are only minor issues.

\section{Cost and Benefit Analysis}

Using the on-ground system proposed, the charge and discharge process can be completed quickly (about one minute) not causing noticeable user delays and allowing one on-ground station to serve many cars. This way, the number of on-ground stations needed (and costs as well) remain low.

Motor efficiency is not noticeably affected by these systems proposed and can even be slightly improved for the exhaust case. Total costs have been roughly estimated by each onboard system installed as 500 dollars (at a commercial production scale), 5,000 dollars for each on-ground station and 3,000 for the building's system modification. Let us consider as example, a neighborhood connected with district heating in which 100 cars are modified and 8 stations are installed in 4 different points. In this case, the total investment required is around 100,000 dollars, around half for the on-ground and the onboard systems. The annual savings expected (regarding, e.g., the current gasoline prices of 8.8 dollars per gallon in Germany) for one car (regarding an average fuel consumption of 35 to 70 gallons per month as we have seen previously) can be roughly estimated between 3,500 and 7,000 dollars. Therefore, the payback period for the 
TABLE 1: Thermal performance for both onboard devices proposed $\left(M=90 \mathrm{~kg}, D=2^{\prime \prime}\right)$.

\begin{tabular}{lcc}
\hline & Cooling system & Exhaust system \\
\hline$T_{h}$ & $90^{\circ} \mathrm{C}$ & $1,000^{\circ} \mathrm{C}$ \\
$Q$ & $18 \mathrm{~kW}$ & $19 \mathrm{~kW}$ \\
$m^{\prime}$ & $0.21 \mathrm{~kg} / \mathrm{s}$ & $0.0173 \mathrm{~kg} / \mathrm{s}$ \\
$U$ & $500 \mathrm{~W} / \mathrm{m}^{2} \mathrm{~K}$ & $50 \mathrm{~W} / \mathrm{m}^{2} \mathrm{~K}$ \\
$10^{\circ} \mathrm{C} \rightarrow 80^{\circ} \mathrm{C}$ & 29 minutes & 34 minutes \\
\hline
\end{tabular}

entire system can be roughly estimated as just two months, and after this, the annual savings is up to 700,000 dollars and seven times the investment made, with only minor operation costs. Beside this, the remarkable economic benefit for the community and the environmental benefits should be considered, among other remarkable political issues, as reducing the national dependence of imported oil fuels. These figures illustrate the tremendous potential, economical as much as environmental, that the large-scale development of this affordable system could be achieved in the world.

\section{Conclusions}

In this paper, a novel conceptual proposal for recovering wasted heat from car engines is presented [8]. Being a wellknown subject already studied, the novelty of this proposal is related to the community's point of view considered here, and using this element for solving the open challenges. Designing an on-ground system that works together with the onboard system, this proposal has found new synergies among them. In this way, the onboard system can remain simple, low cost, and universal; meanwhile, the on-ground system can manage the interface between users and building heating system, and providing an elegant solution for the water thermal expansion problem as well.

This last concern maybe was the reason why car manufacturers have been reluctant to adopt these systems. Regarding this point, a major advantage of this proposal is that this could be completely developed and applied independent of the car industry. This advantage is the key to the real application of this proposal on a large scale.

This technology could reach a huge impact on our present energy consumption, and its perspective is even better, by matching the present car boom. Furthermore, two preliminary new proposals were presented, that could improve noticeably the future results following this line of research.

The UN's International Panel on Climate Change has recently launched its fourth report in Bangkok. Its headline finding is that without action global greenhouse gas emissions will be $25 \%$ to $90 \%$ above current levels by the year 2030, with the highest growth levels in the transport sector. Moreover, while experts projected that fuel cell vehicles will not have an appreciable development, this proposal is still completely compatible with cars fueled by hydrogen, in the most probable future scenario using combustion engines.

As was pointed out by experts, the role of civilization to manage the immense challenge of building a sustainable society depends on the strengths of the "social technology" composed of the business sector, government, and legislation, as well as on the wit and will of society to integrate all of these elements in pursuit of the goal for sustainable well being. This proposal goes clearly in this direction beyond our present behaviors.

\section{References}

[1] “The Automobile. New Book of Popular Science," in Number of Cars. The Physics Factbook, G. Elert, Ed., Grolier, Republic of China, 6th edition, 1978.

[2] World Business Council for Sustainable Development, International Energy Agency, Sustainable Mobility Project.

[3] Mark's Standard Handbook for Mechanical Engineers, 10th edition, 1995.

[4] Z. G. Sun, "Energy efficiency and economic feasibility analysis of cogeneration system driven by gas engine," Energy and Buildings, vol. 40, no. 2, pp. 126-130, 2008.

[5] "Improvements in Heating Apparatus for Automobiles," Great Britain invention patent $N^{\circ}$ GB191020558, application date 1911-08-31.

[6] "Water heating device in a water tank of a special purpose vehicle for reducing the production cost by heating selectively the water contained in the water tank by using the water of a radiator for engine coolant," South Korean invention patent No KR20050015322, application date 2005-02-21, given to KIA Motors Corporation.

[7] F. Incropera and D. DeWitt, Fundamentals of Heat and Mass Transfer, John Wiley and Sons, New York, NY, USA, 6th edition, 2007.

[8] L. Juanicó, "Method for charge and discharge of liquids for space heating from energy wasted in combustion motors," Argentinean Invention patent P080104377, 2008. 

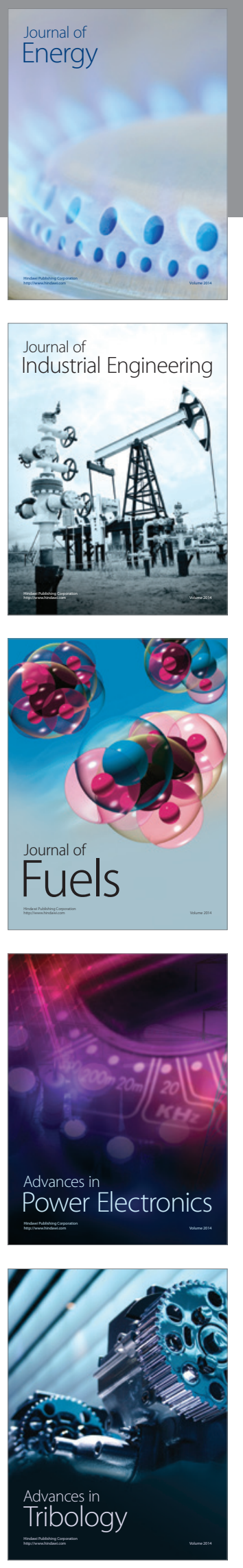
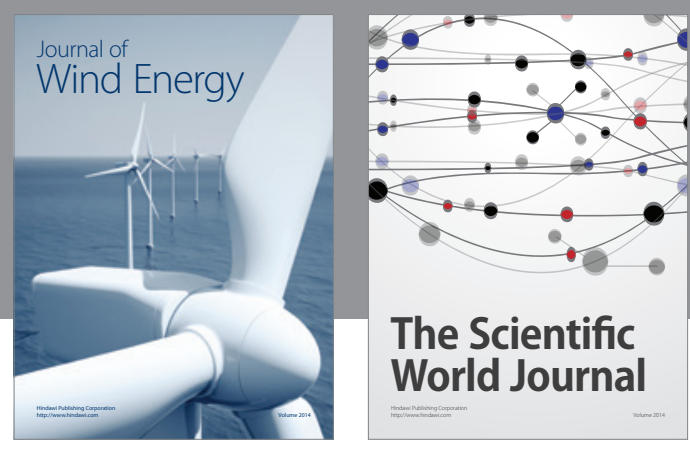

The Scientific World Journal

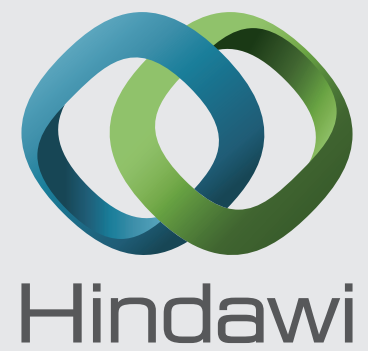

Submit your manuscripts at http://www.hindawi.com
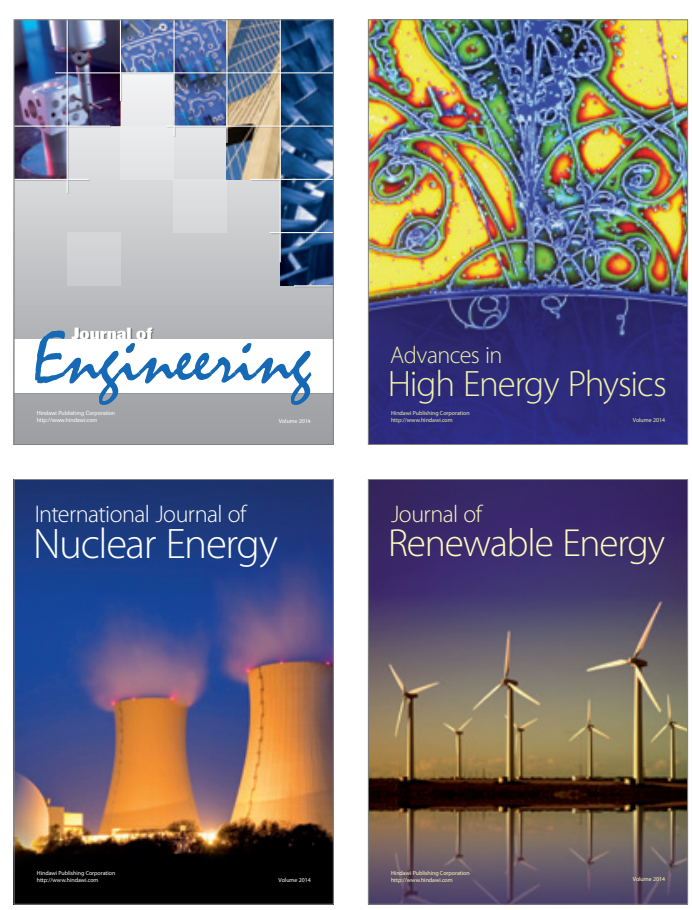

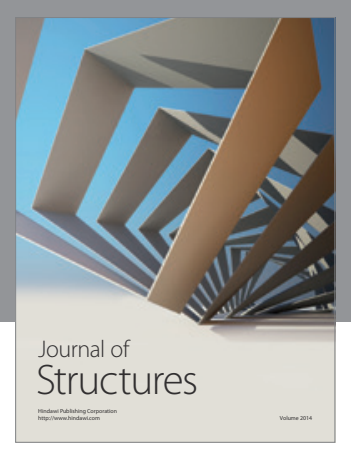

Rotating
Mechinery
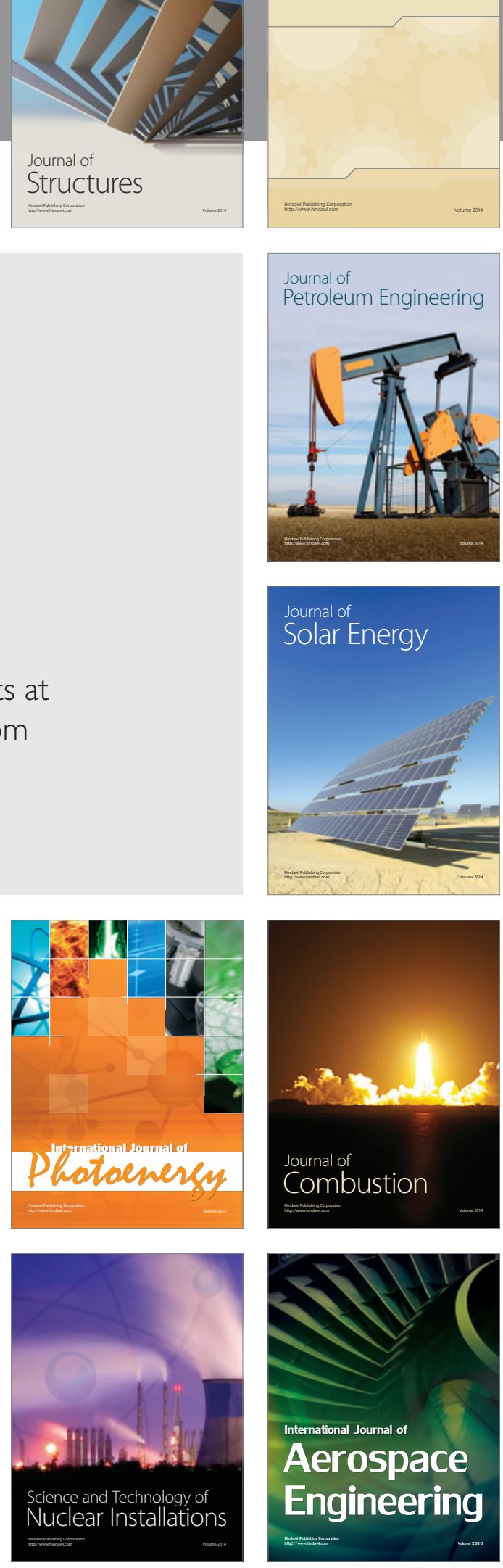